\title{
PERANCANGAN ALTERNATIF SIGN SYSTEM SEBAGAI INFORMASI LOKASI PENJUALAN DI PASAR LEGI KOTA GEDE
}

\author{
MS. Andrijanto \\ Program Studi Desain Komunikasi Visual \\ Fakultas Bahasa dan Seni, Universitas Indraprasta PGRI \\ Jl. Nangka No. 58 C Tanjung Barat Jagakarsa, Jakarta Selatan \\ ad3_410@yahoo.com
}

\begin{abstract}
Abstraks
Pasar tradisional adalah tempat transaksi secara langsung antara konsumen dengan penjual. Fungsi pasar tradisional saat ini tidak hanya tempat terjadinya jual beli, tetapi juga sudah berkembang sebagai tempat yang multifungsi dan bertemunya masyarakat sosial dan budaya. Salah satu permasalahan pokok di Pasar Legi Kotagede adalah kurangnya signage atau tanda yang memudahkan para pembeli untuk mencari tempat maupun arah jalan ke lapak pedagang, yang menyebabkan ketidak nyamanan bagi pembeli terlebih bagi pengunjung yang baru datang ke Pasar Legi Kotagede Yogyakarta. Sign system adalah sebuah sistem penandaan yang sesuai dengan kebudayaan warga masyarakatnya, selain sebagai petunjuk, penamaan, penyampaian informasi singkat, dapat juga berupa aturan-aturan atau norma-norma yang dipakai dan diakui pada tempat tertentu dan dapat dimengerti oleh warga masyarakatnya (Kartika, 2010: 223). Perancangan sign system pada pasar Legi Kotagede menggunakan salah satu ornamen yang terdapat pada petunjuk tempat di wilayah Kotagede, ornamen yang peneliti gunakan adalah ornamen Lung-lungan. Motif Lunglungan (sulur) adalah motif ukir berupa tumbuh-tumbuhan berujud sulur atau tumbuhan yang menjalar dengan untaian daun dan pucuk batang muda. Bentuk motif Lunglungan bervariasi, adapun jenis pohonpohon yang sering distilir untuk hiasan. Lunglungan adalah teratai (padma), daun kluwih, bunga melatih, pohon bunga dan daun markisah, buah keben, tanaman rambat atau tanaman-tanaman yang bersifat melata dan beringin (Ismunandar dalam Dorno, 2014:72).
\end{abstract}

Kata kunci : pasar tradisional, sistem rambu, ornamen Lung-lungan

\section{SIGN SYSTEM ALTERNATIVE DESIGNING AS SALES INFORMATION SALES IN THE LEGI MARKET OF KOTAGEDE}

\begin{abstract}
Traditional markets are places of direct transactions between the consumer and the seller. The function of traditional markets today is not only the place of buying and selling, but also has developed as a multifunctional place and the meeting of social and cultural society. One of the main problems in Pasar Legi Kotagede is the lack of signage or a sign that facilitates the buyer to find the place or the way to the traders, which causes inconvenience for the buyer especially for new visitors coming to Legi Market Kotagede Yogyakarta. Sign system is a marking system that is in accordance with the culture of its citizens, other than as a guide, naming, delivery of brief information, can also be the rules or norms used and recognized in certain places and can be understood by the community (Kartika, 2010: 223). The design of sign systems on the market Legi Kotagede using one of the ornaments found in the directions place in the area Kotagede, ornaments that researchers use is ornament Lung-lungan. Lung-lungan motif (vine) is carving motif in the form of vegetation spreading or spreading plants with leaf strand and shoot young stems. Lunglungan motif shape varies, as for the type of trees that are often distilir for decoration. Lunglungan is a lotus (padma), kluwih leaves, flower trains, flower trees and leaves of citrus, fruit keben, vines or creeping and banyan plants (Ismunandar 1993: 63).
\end{abstract}

Keywords : traditional markets, sign systems, Lung-lungan ornamen 


\section{PENDAHULUAN}

Pasar tradisional adalah tempat proses transaksi secara langsung antara penjual dan pembeli. Proses transaksi jual-beli dilakukan melalui proses tawar menawar antara pembeli dan penjual, dan harga yang ditawarkan untuk suatu barang bukan harga tetap, hal ini yang membedakan antara pasar tradisional dengan pasar modern. Barang yang tersedia di pasar tradisional merupakan bahan-bahan pokok dan barang kebutuhan rumah tangga yang kadang di pasar modern tidak ada. Pasar tradisional berlokasi ditempat terbuka atau bahkan pedagang menjual barang dagangannya dipingir jalan.

Ciri khas dari pasar tradisional adalah adanya tenda dan meja tempat penjual menjajakan dagangannya dan belum menggunakan etalase, serta hilir mudiknya pembeli yang berjalan untuk melihat, memilih dan menawar barang yang akan dibelinya. Pasar tradisional tidak hanya tempat proses terjadinya jual beli, tetapi juga dapat menjadi tempat yang multifungsi dan memiliki fungsi sosial dan budaya.

Menurut Oktavia (2007) pasar tradisional berdasarkan jenis kegiatannya digolongkan menjadi tiga jenis:

1. Pasar eceran yaitu pasar dimana terdapat permintaan dan penawaran barang secara eceran.

2. Pasar grosir yaitu pasar dimana terdapat permintaan dan penawaran dalam jumlah besar.

3. Pasar induk yaitu pasar yang lebih besar dari pasar grosir, merupakan pusat pengumpulan dan penyimpanan bahan-bahan pangan yang akan disalurkan ke grosir-grosir dan pusat pembelian.

Semua daerah yang ada di Indonesia memiliki pasar tradisional, begitupun dengan Yogyakarta yang memiliki pasar tradisional yaitu Pasar Legi Kotagede Yogyakarta. Pasar Legi Kotagede adalah pasar tradisional yang sudah ada sejak jaman Panembahan Senopati masih aktif hingga kini.

Pasar Kotagede telah berdiri sejak abad 16. Pasar ini juga kerap disebut Pasar Legi, karena puncak keramaiannya selalu terjadi pada hari-hari pasaran Legi (Legi adalah nama salah satu hari dalam kalender Jawa). Pada hari pasaran Legi itu, pasar akan penuh sesak oleh penjual dan pembeli, bahkan area pasar bisa semakin melebar jauh melebihi area pasar sebenarnya. Berbagai jenis barang dagangan (komoditas dagangan) yaitu dari sayur-sauran, alat-alat pertanian, berbagi hewan unggas hidup seperti burung yang pandai berkicau, pakan ternak, bibit tanaman, pernak-pernik aksesoris kebutuhan rumah tangga, batu akik, berbagai ramuan obat tradisional hingga mebel dapat ditemui di pasar ini. Pasar ini berada di desa Tegalgendu, tepat berada di seberang sungai Gajah Wong ini memang berada di sebuah kawasan kota tua di Yogyakarta. (Yayah dan Andrijanto, 2017 : 103)

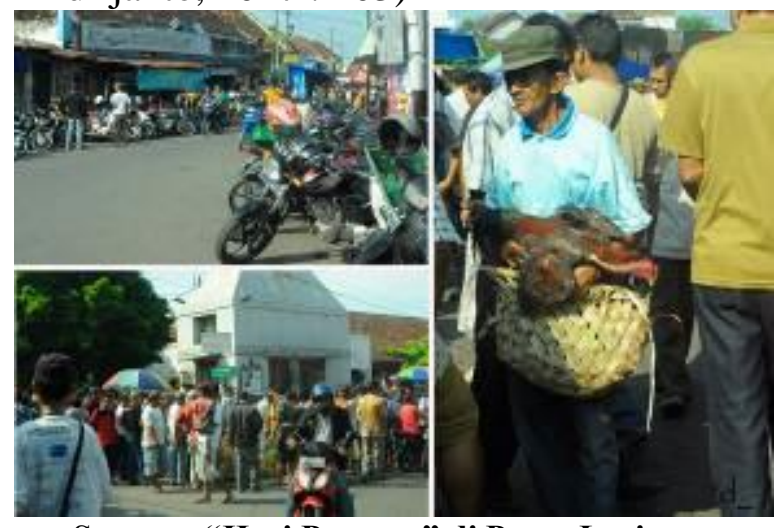

$$
\begin{gathered}
\text { Suasana "Hari Pasaran" di Pasar Legi } \\
\text { Kotagede } \\
\text { (sumber : dokumentasi peneliti) }
\end{gathered}
$$

Berdasarkan hasil pengamatan peneliti mengenai sistem tanda/ signage di Pasar Legi Kotagede Yogyakarta, terdapat beberapa pokok permasalahan yang peneliti temui. Salah satu permasalahan pokok di Pasar Legi 
Kotagede adalah kurangnya signage atau tanda yang memudahkan para pembeli untuk mencari tempat maupun arah ke lapak pedagang yang dituju, yang mengakibatkan ada rasa kurang nyaman dari pengunjung terlebih bagi pengunjung yang baru datang ke Pasar Legi Kotagede Yogyakarta.

Banyak pengunjung yang kesulitan untuk menemukan tempat pedagang yang menjual produk-produk tertentu, sehingga membuat pengunjung membutuhkan waktu yang lebih lama untuk mendapatkan produk yang ingin dibelinya.

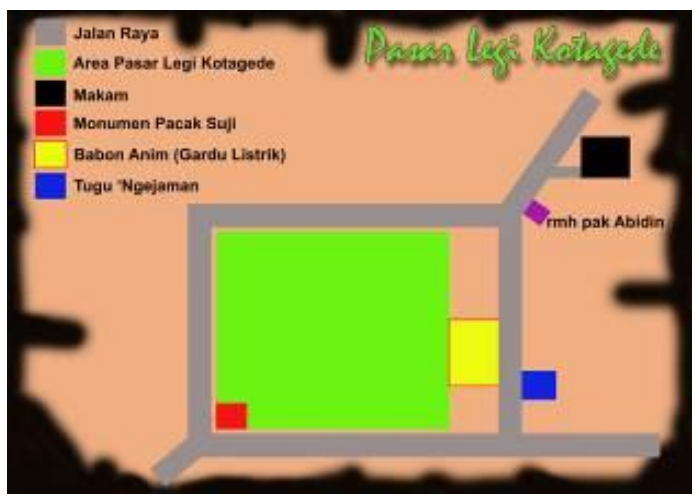

Denah Pasar Legi Kotagede

(sumber : dokumentasi peneliti)

Sistem alur yang ada di Pasar Kotagede pun masih kurang jelas, ketika jam ramai, pasar terlihat sangat penuh dan pembeli sedikit berdesak-desakan untuk berjalan terlebih pada hari pasaran Legi, disamping faktor jalan yang cukup sempit di dalam pasar dan juga diluar pasar atau trotoar pasar digunakan juga untuk berjualan.

Penelitian terdahulu oleh peneliti mengenai studi penciptaan produk dalam bentuk perangkat peralatan pasar tradisional yang memudahkan para penjaja atau pedagang dalam menjajakan barang dagangnya yang menghasilkan kesimpulan apabila alternatif rancangan produk ini digunakan oleh masyarakat akan memudahkan para pedagang dalam penyimpanan barang dagangannya.
Untuk penelitian kali ini peneliti tetap mengangkat objek Pasar Legi Kotagede, dengan membahas signage atau sistem rambu pada pasar legi Kotagede.

Model penelitian ini berbasis penciptaan dengan Laeyendecker dalam Ratna (2010: 285) mengatakan bahwa model visual pada umumnya merupakan rekonstruksi kenyataan secara material dapat diraba seperti peta, dokumen dan gedung atau bangunan-bangunan lain. Dalam rangka menjelaskan struktur visual pada wayang kulit, maka berikut ini adalah proses penelitian kualitatif dalam upaya mengungkap konstruksi realita dan nilai yang terkandung di dalamnya melalui visual.

Model atau pola penelitian ini bersifat penciptaan, hal itu dikarenakan ketika ekspresi sebagai bentuk pengungkapan perasaan atau pernyataan terdalam ke dalam wujud yang bisa diamati maka proses pewujudannya membutuhkan metode dan teknik. Selanjutnya, Hawkins dalam Gustami (2004) menjelaskan bahwa metode penciptaan terdiri atas tahapan penciptaan berupa: (1) eksplorasi ide, (2) improvisasi/eksperimentasi, dan (3) pewujudan. Dalam konteks ini, intuitif sebenarnya telah berada dalam wilayah improvisasi/ eksperimentasi dan pewujudan.

\section{PEMBAHASAN}

\section{Sistem Rambu (Signage)}

Salah satu bagian esensial dari environment graphic design adalah signage. Signage merupakan rangkaian representasi visual dan simbolik grafik. yang bertujuan sebagai media interaksi antara manusia dengan ruang publik. (Tinarbuko, 2008: 12). Jika dilihat dari bahasanya, signsystem berasal dari bahasa inggris, yaitu "sign" yang berarti tanda atau lambang, dan "system" yang 
berarti aturan. Signage berfungsi sebagai salah satu media untuk memberi informasi mengenai suatu petunjuk, peringatan, ataupun larangan.

Kebutuhan akan suatu signage/sistem informasi berupa tanda petunjuk arah yang baik semakin berkembang, khususnya bagi kerumunan massa (masyarakat) yang membutuhkan informasi petunjuk arah. Informasi yang disampaikan dalam signage sendiri bersifat deskriptif karena memang ditujukan untuk membedakan orang dan tempat secara khusus dan jelas. Hal ini dilakukan dengan mengelompokkan tempat dan memberikan nama pada tempat atau ruang. Informasi yang dikandung oleh informasi lingkungan ialah informasi tentang lokasi (Passini, 1984) dalam Tanuwidjaja (2012:15).

Sign system adalah sebuah sistem penandaan yang sesuai dengan kebudayaan warga masyarakatnya, selain sebagai petunjuk, penamaan, penyampaian informasi singkat, dapat juga berupa aturan-aturan atau norma-norma yang dipakai dan diakui pada tempat tertentu dan dapat dimengerti oleh warga masyarakatnya (Kartika, 2010: 223).

Sistem rambu merupakan alat komunikatif bagi masyarakat dalam mengetahui area, ruangan maupun suatu lokasi yang ingin diketahui oleh masyarakat. Sistem rambu sangat diperuntukkan agar masyarakat dipermudah aktivitasnya. Hasil perancangan yang dilakukan adalah menciptakan Sistem Rambu (Signage) Pasar legi Kotagede Yogyakarta, perancangan sistem rambu berfungsi sebagai berikut :

1. Sebagai cara untuk mengelompokkan para pedagang yang ada di daerah Pasar Legi Kotagede berdasarkan ikon atau simbol visual perangkat dagangnya.

2. Untuk mempermudah akses informasi bagi masyarakat dalam berbelanja di daerah Pasar Legi
Kotagede Yogyakarta sehingga berbelanja menjadi terarah dan teratur.

3. Sebagai pengingat unsur ikon berupa ornamen hingga jenis peralatan tradisional yang ditampilkanndalam signage tersebut, hal itu dilakukan agar menghubungkan dengan konsep sejarah dan kebudayaan masyarakat setempat. Sehingga para wisatawan maupun pendatang mengetahui ikonikon yang ada di signage dipilih karena kekuatan kebudayaan visual setempat.

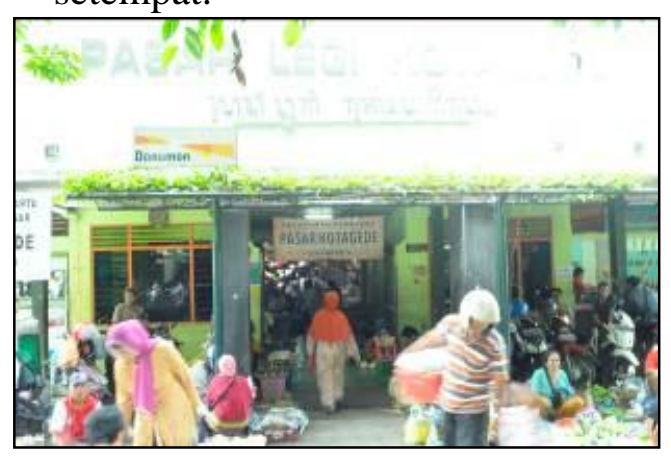

Pintu Masuk Pasar

(sumber : dokumentasi peneliti)

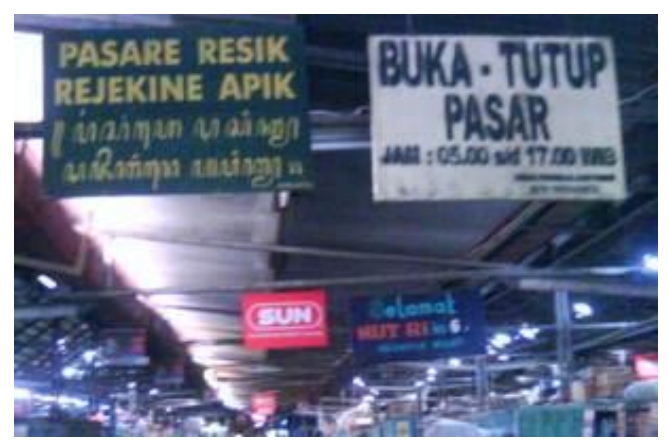

Keterangan Jam Buka Pasar

(sumber : dokumentasi peneliti)

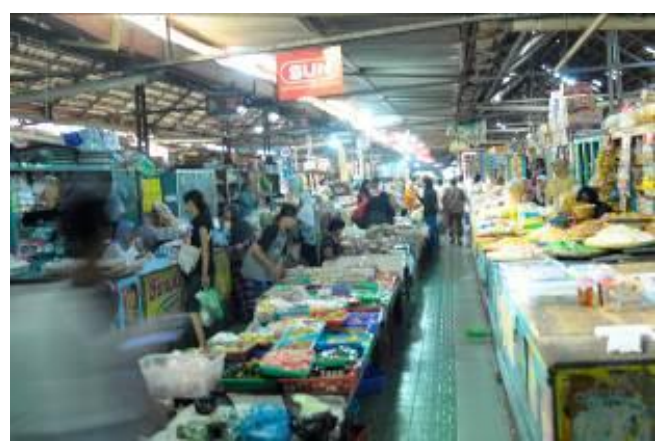

Lorong antara penjual jajanan pasar dan sembako

(sumber : dokumentasi peneliti) 


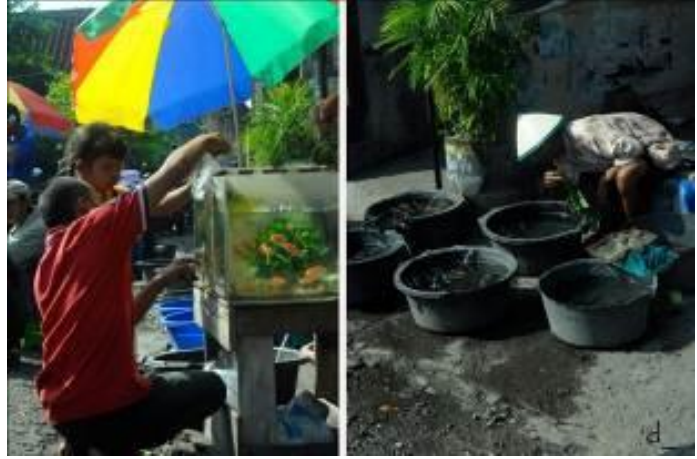

.Area Pedagang Ikan Hias

(sumber : dokumentasi peneliti)

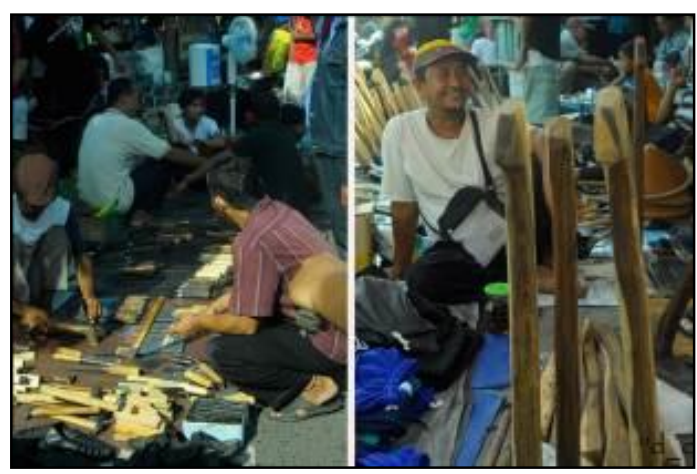

Area Pedagang Perkakas

(sumber : dokumentasi peneliti)

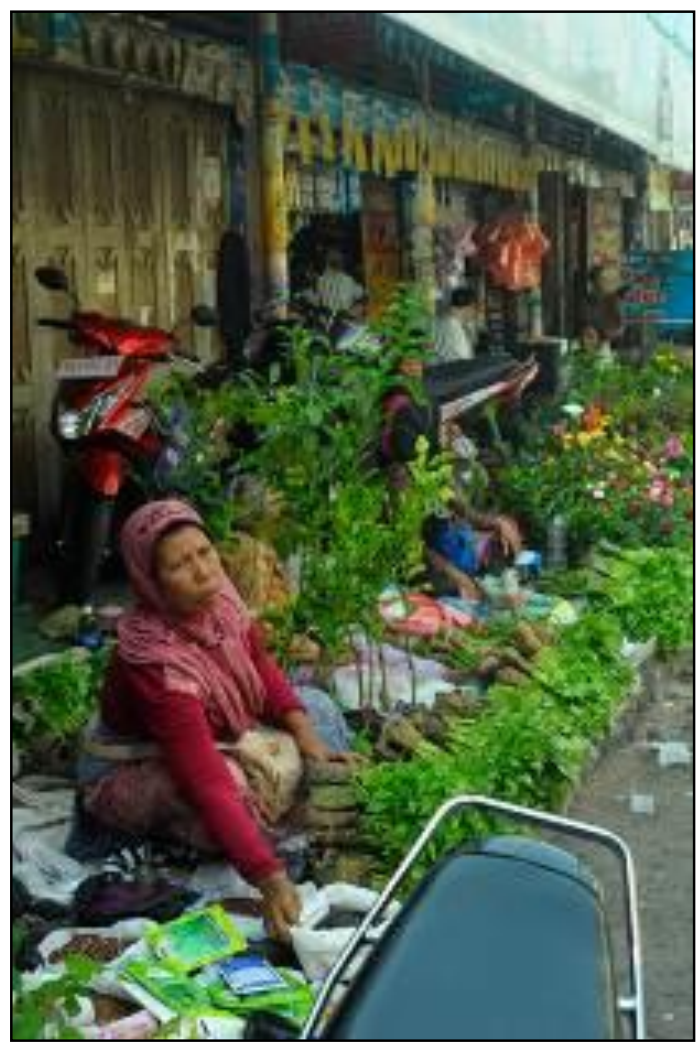

Area Pedagang Tanaman Hias

(sumber : dokumentasi peneliti)

\section{Konsep Perancangan}

Pandangan pasar tradisional yang kurang baik seperti kumuh, kotor, bau dan tak tertata rapi menjadi tugas pemerintah untuk segera mungkin merevitalisasi pasar tradisional karena disini berhubungan dengan hidup orang banyak. Revitalisasi pasar tradisional untuk dijadikan tempat berbelanja yang nyaman, menarik dan bercitra positif merupakan suatu tantangan yang cukup berat yang harus diupayakan oleh pemerintah sebagai rasa tanggung jawab kepada publik dalam hal ini masyarakat.

Sebagai sebuah pasar yang kuat sekali identitasnya di wilayah Yogyakarta, maka peneliti jabarkan beberapa kegiatan di daerah Pasar Legi yang ada di Yogyakarta.

Tabel 1 Jadwal Kegiatan Pasar Legi Yogyakarta

\begin{tabular}{lllll}
\hline NO & WAKTU & LOKASI & $\begin{array}{l}\text { KEGIATAN } \\
\text { JUALAN }\end{array}$ \\
\hline 1 & $05.00-15.00$ & $\begin{array}{l}\text { Area } \\
\text { dalam/luar }\end{array}$ & $\begin{array}{l}\text { Kegiatan } \\
\text { normal }\end{array}$ & jualan \\
\hline 2 & $14.00-21.00$ & Barat pasar & $\begin{array}{l}\text { Jajan pasar } \\
\text { (makanan kecil) }\end{array}$ \\
\hline 3 & $16.00-21.00$ & Utara pasar & Lauk pauk \\
\hline 4 & $17.00-21.00$ & Utara pasar & Kuliner - Lauk pauk \\
\hline 5 & $17.00-21.00$ & Timur pasar & Pakaian, Buku \\
\hline 6 & $18.00-22.00$ & Timur/Selatan & $\begin{array}{l}\text { Klithikan } \\
\text { Yard) }\end{array}$ \\
\hline 7 & $21.00-03.00$ & Utara pasar & $\begin{array}{l}\text { Kuliner, minuman } \\
\text { (Wedang Ronde) }\end{array}$ \\
\hline
\end{tabular}

Berdasarkan hasil pengamatan peneliti ke Pasar Legi Kotagede, mengamati kondisi pasar, maka peneliti menentukan posisi dari signage yang akan dibuat dan di tempatkan pada tiangtiang di dalam pasar. Berikut foto-foto hasil penelitian kondisi dan penempatan signage nantinya : 


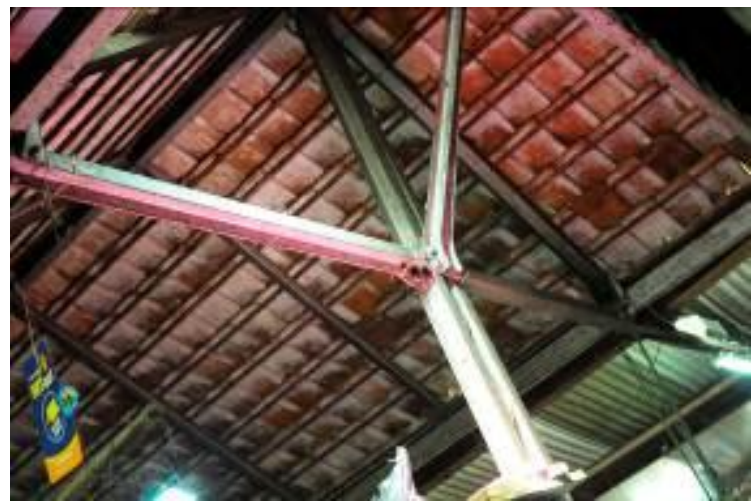

Tiang di dalam Pasar (sumber : dokumentasi peneliti)

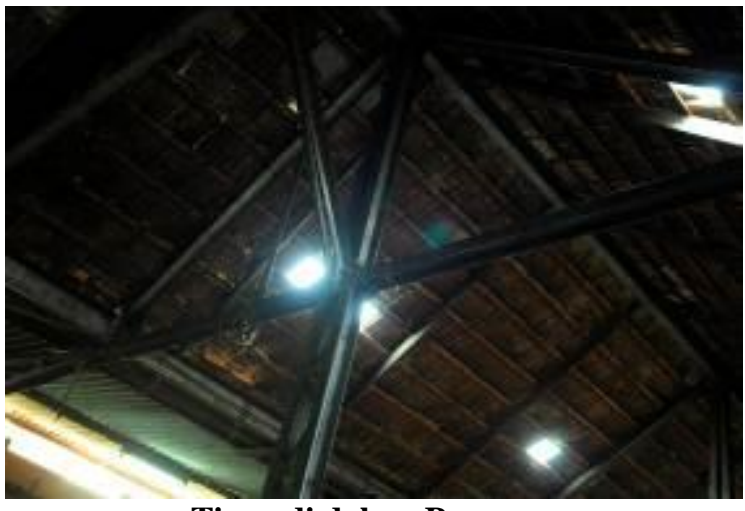

Tiang di dalam Pasar

(sumber : dokumentasi peneliti)

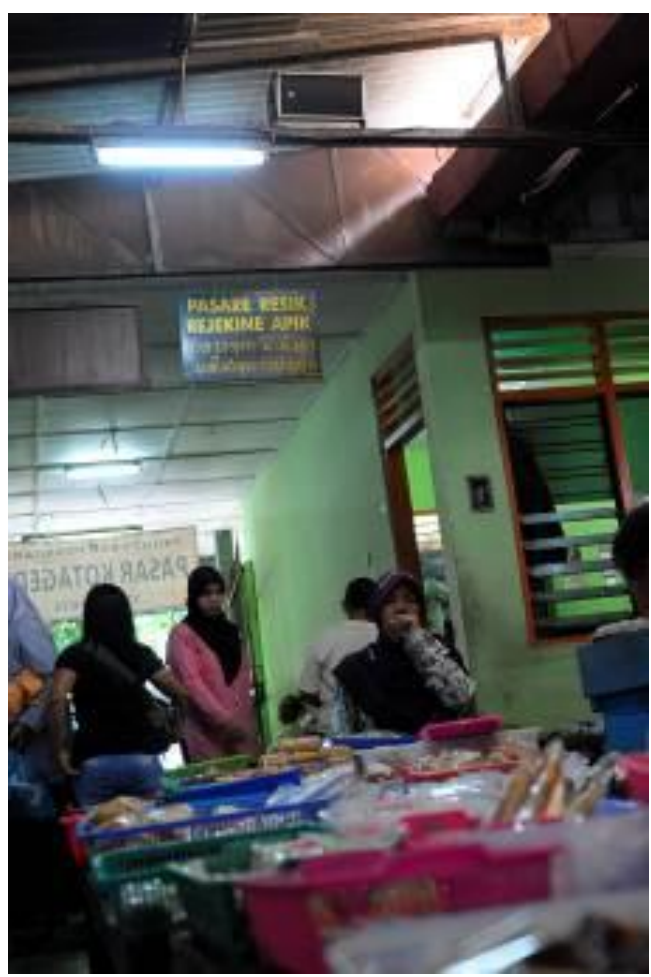

Salah satu signage

(sumber : dokumentasi peneliti)

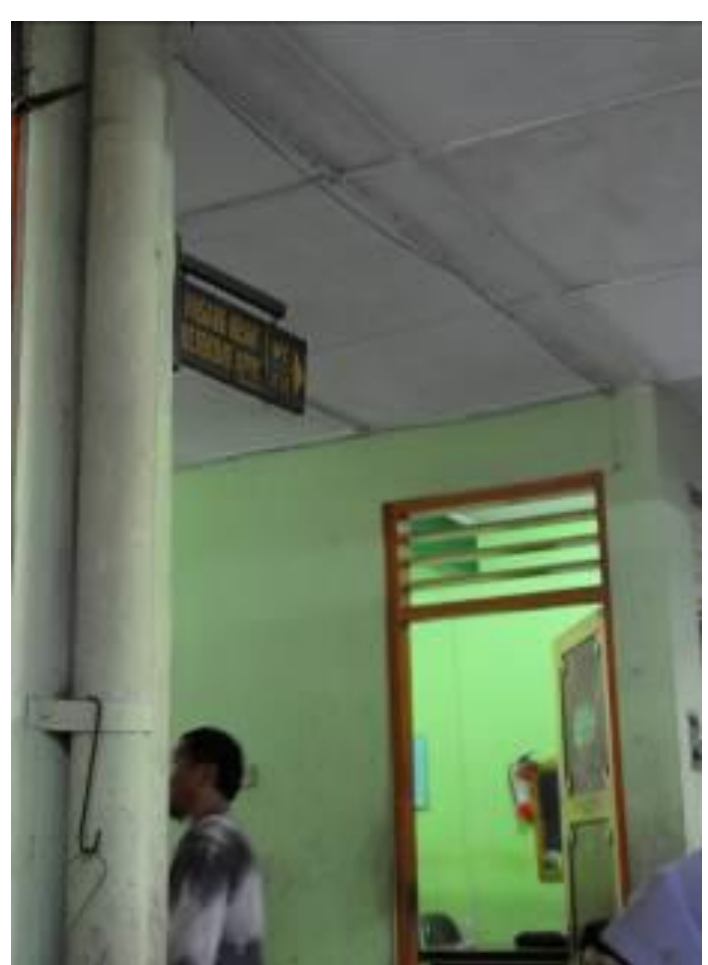

Petunjuk Arah ke Toilet

(sumber : dokumentasi peneliti) 


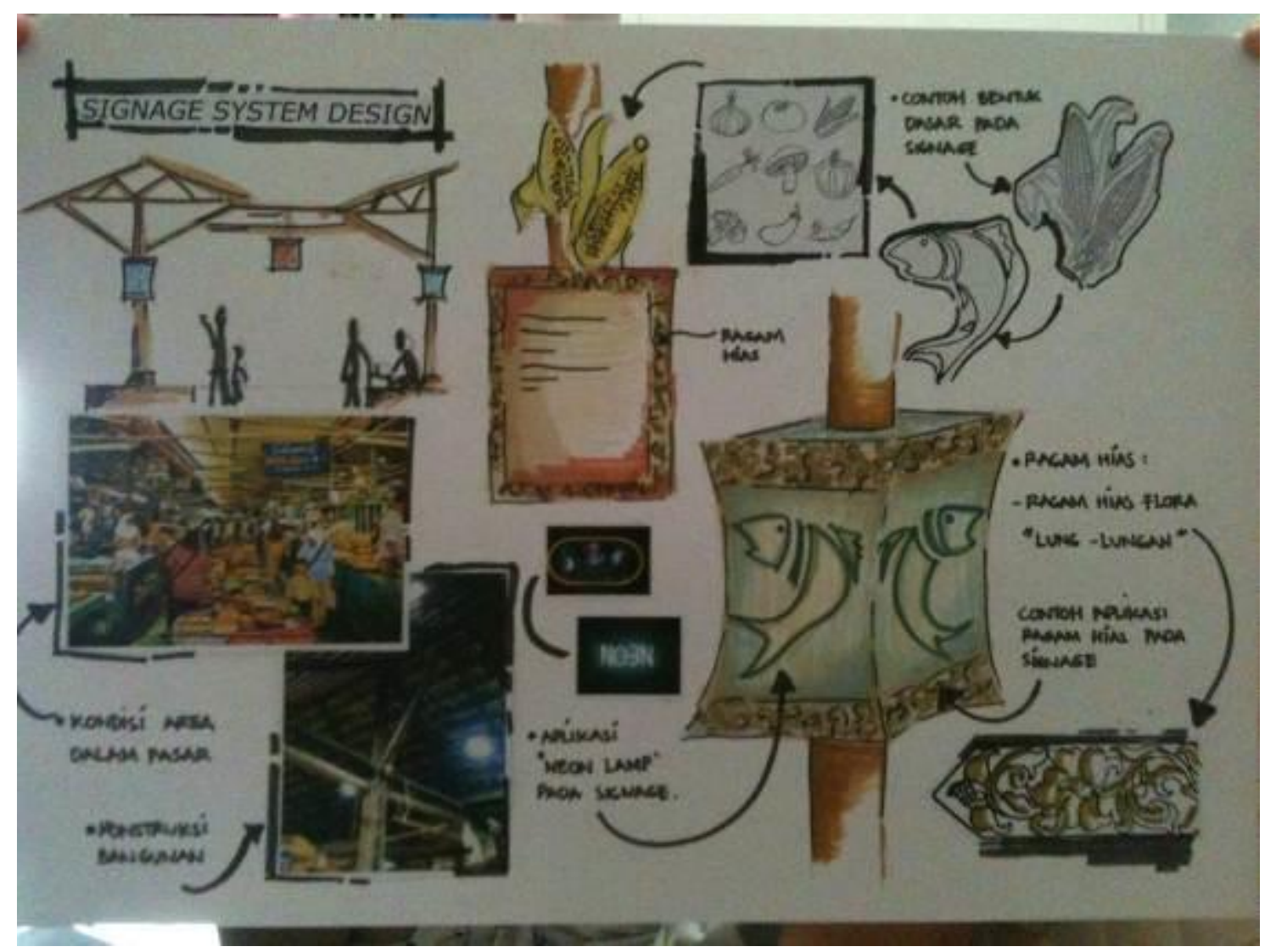

Sketsa Perancangan Signage Pasar Kotagede (sumber : dokumentasi peneliti)

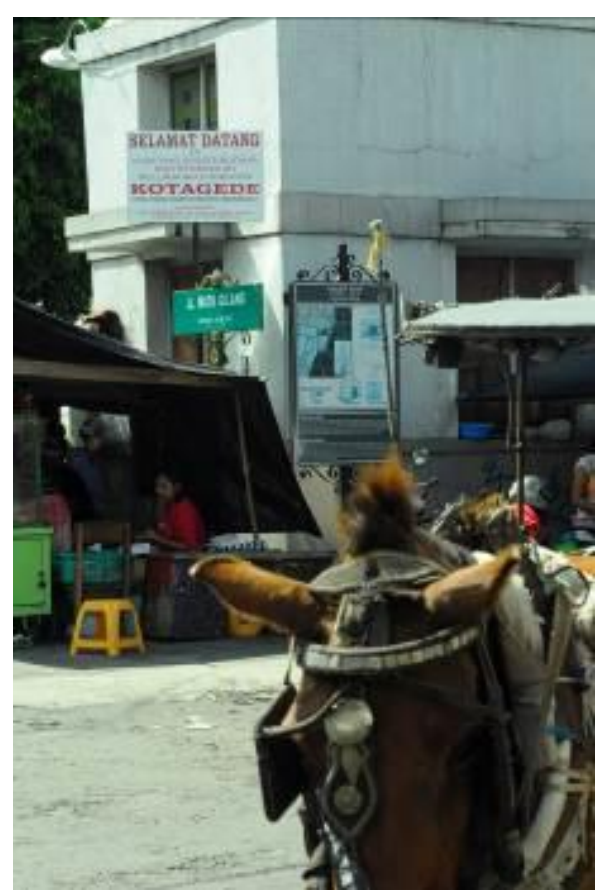

Petunjuk arah dan Selamat Datang

(sumber : dokumentasi peneliti) 


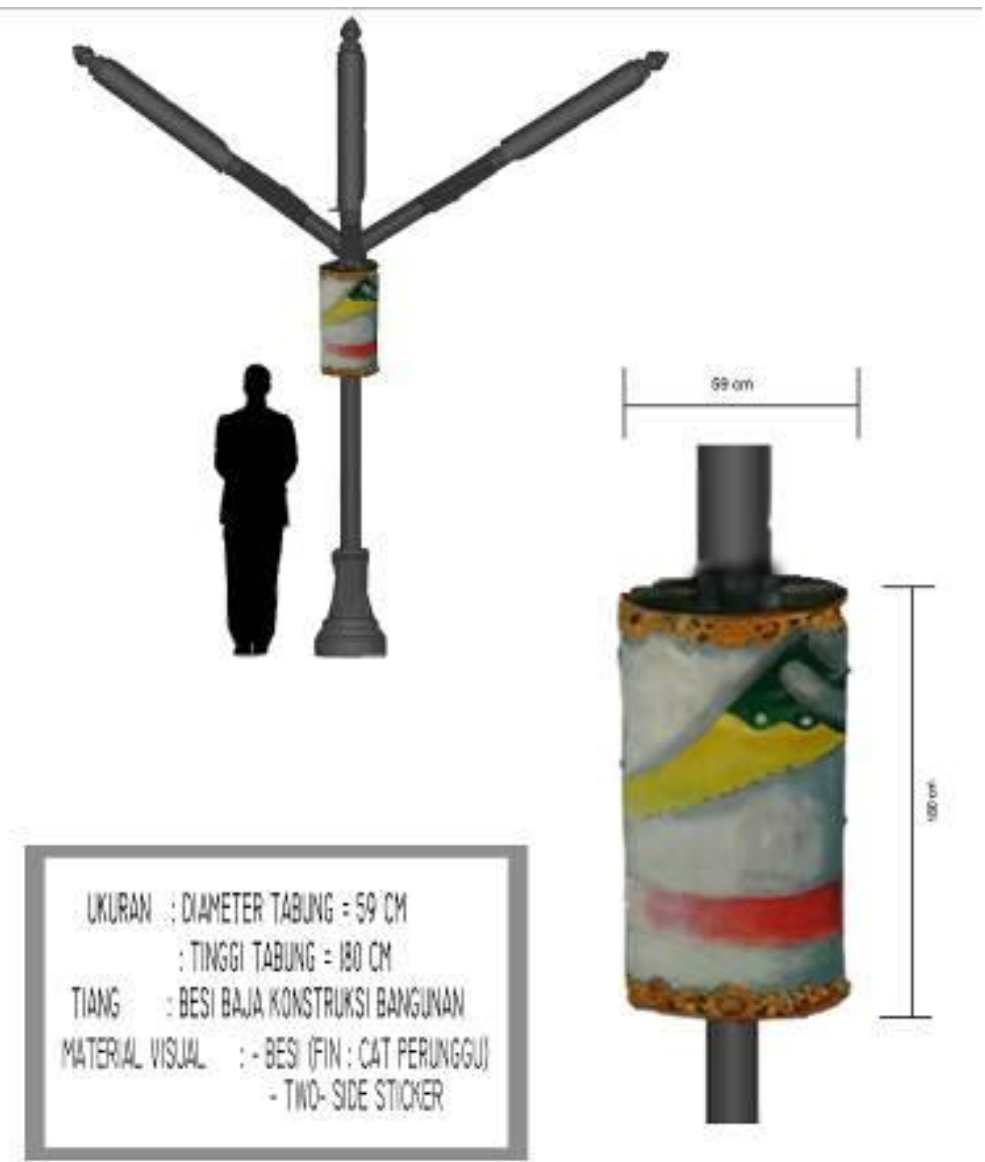

Sketsa Perancangan Signage Pasar Kotagede (sumber : dokumentasi peneliti)

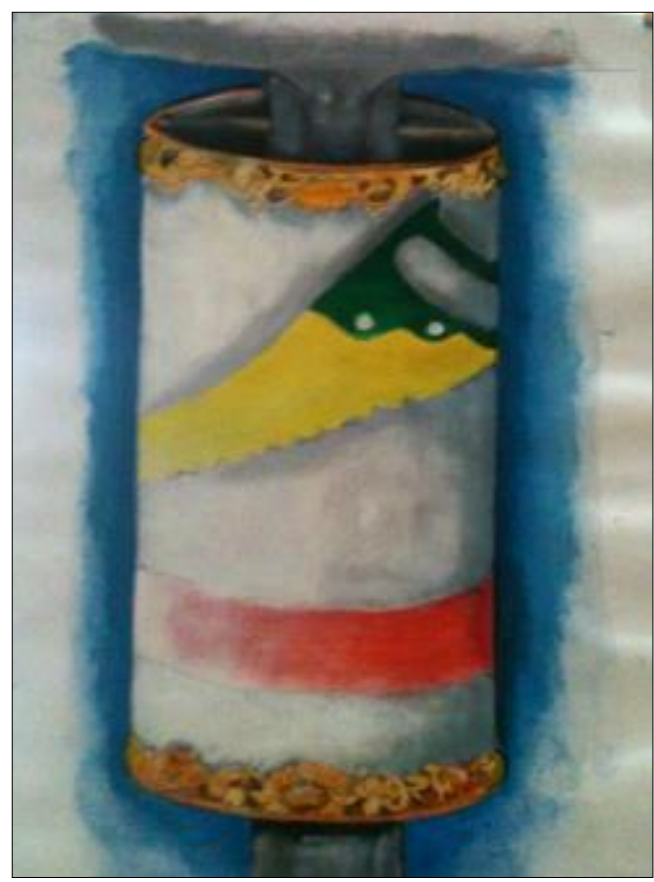

Sketsa Signage untuk Kelompok Dagang Peralatan Pertukangan (sumber : dokumentasi peneliti) 
Dari gambar tersebut, dapat diuraikan konsepnya sebagai berikut:

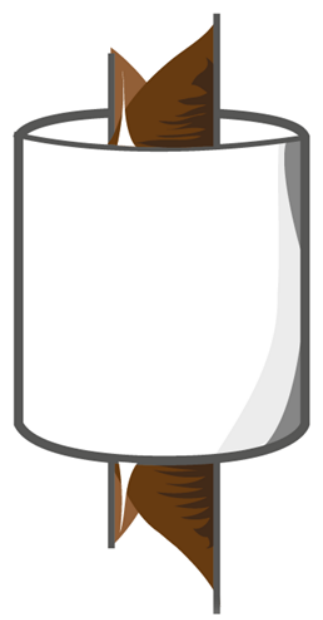

Sketsa Dasar Signage untuk Kelompok Dagang

(Sumber: dokumentasi peneliti)

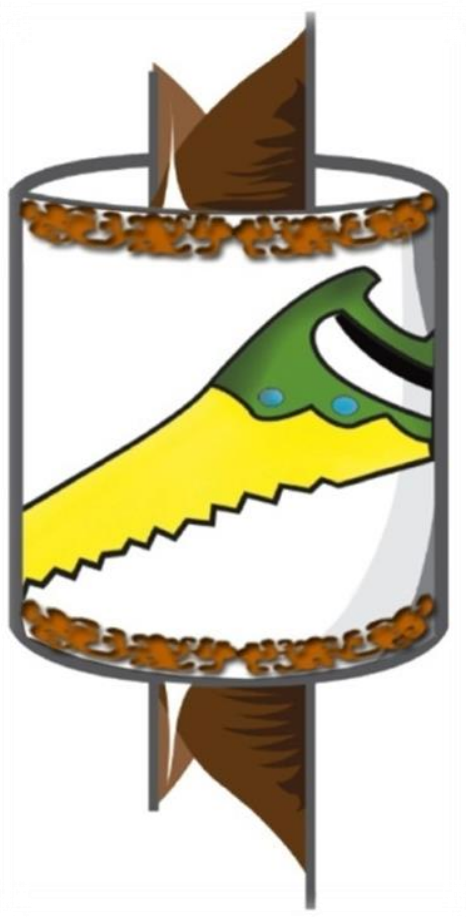

Sketsa Signage untuk Kelompok Dagang Peralatan Pertukangan

(Sumber: dokumentasi peneliti)

\section{Konsep Visual}

Untuk perancangan signage atau sistem rambu pada pasar legi Kotagede, peneliti menggunakan salah satu ornamen pada plang informasi tempat yang terdapat disekitar pasar Kotagede.

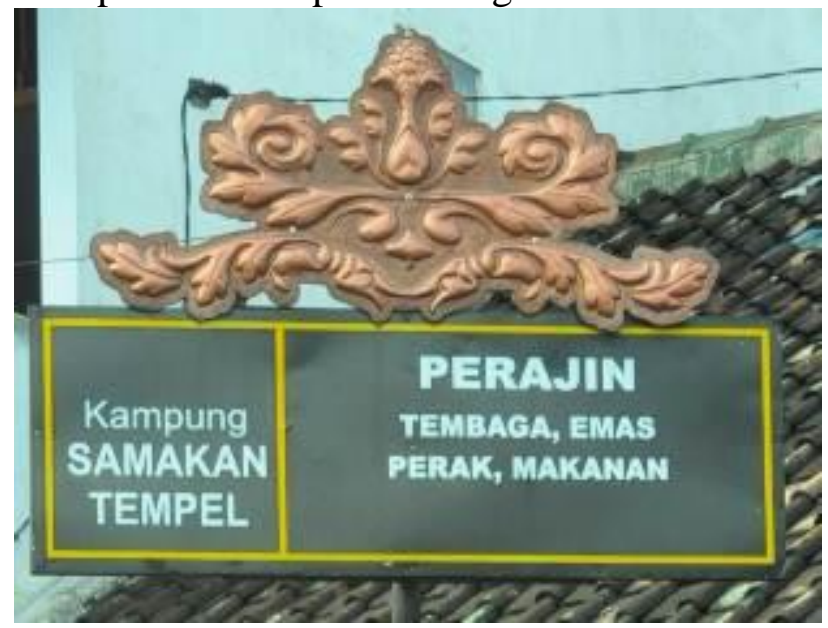

Referensi Ornamen

(Sumber: dokumentasi peneliti)

Menurut Soepratno (1997: 11) menjelaskan ornamen berasal dari bahasa Yunani yaitu dari kata ornare yang berarti hiasan atau perhiasan. Ragam hias atau ornamen terdiri dari berbagai jenis motif. Motif-motif itulah yang digunakan untuk menghias atau menambahkan sesuatu yang ingin kita hias. Oleh karena itu, motif merupakan dasar untuk membuat sesuatu ornamen. Ornamen digunakan untuk menghias atau menambahkan sesuatu bidang atau benda, sehingga benda tersebut menjadi indah seperti yang dapat dilihat pada hiasan sampul buku, piagam, kain batik, tempat bunga dan barang-barang lainnya.

Motif ornamen yang digunakan pada signsystem di Kotagede, menggunakan ornamen Lung-lungan. Motif Lung-lungan (sulur) adalah motif ukir berupa tumbuh-tumbuhan berujud sulur atau tumbuhan yang menjalar dengan untaian daun dan pucuk batang muda. Motif lung-lungan termasuk dalam salah satu dari motif batik. Lung-lungan berasal dari kata ulung-ulung dan tetulung yang bermakna dermawan dan menolong, sehingga lung-lungan mempunyai makna bahwa seorang muslim (Sultan Agung sudah memeluk 
Islam) harus mempunyai jiwa sosial yang baik atau kesalehan sosial dengan suka membantu sesama dan mempunyai sifat dermawan. Sulur atau lung-lungan mengandung harapan agar kehidupan dan rejeki yang selalu datang berkesinambungan dan tidak pernah putus diberikan kepada manusia (http://mesjidgedhe.or.id/filosofi-ukirandan-ornamen/).

Kata lung-lungan berasal dari kata lung dan ulung-ulung. Kata lung yang berarti batang tumbuhan melata yang masih muda yang berbentuk melengkung, bagiannya terdiri dari bentuk tangkai, daun, bunga, dan buah yang dilukiskan secara distilisasi. Kalau pada rumah tradisional ornamen Lunglungan dapat ditemukan pada balok kerangka rumah, pemindangan, tebeng jendela, daun pintu, patang aring, dan lain sebagianya. Fauzan (wawancara 25 Mei 2014) mengatakan bahwa ornamen Lunglungan adalah ornamen bermotif tumbuhan rambat. Fungsi ornamen Lunglungan terutama untuk memberikan keindahan pada suatu bangunan (Yulia dalam Jeksi Dorno, 2014: 72).

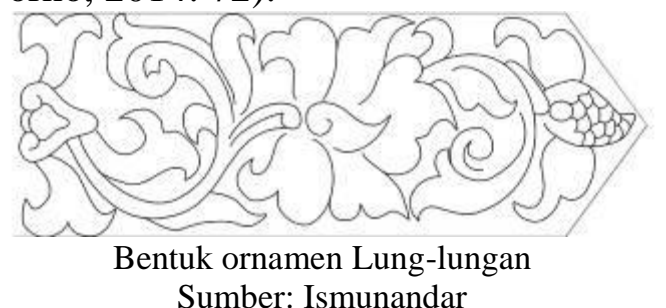

Bentuk motif Lunglungan variasi, adapun jenis pohon-pohon yang sering distilir untuk hiasan Lunglungan adalah teratai (padma), daun kluwih, bunga melatih, pohon bunga dan daundaun markisah buah keben, tanaman rambat atau tanaman-tanaman yang bersifat melata dan beringin. Ornamen Lunglungan biasanya untuk memberikan kesan keindahan dan kesakralan, walaupun kadan terlihat angker atau wingit (Ismunandar dalam Jeksi Dorno, 2014: 72).
Dari penjelasan tersebut menandakan bahwa ornamen merupakan ragam hias yang menghiasi suatu bidang atau benda, supaya suatu bidang atau benda tersebut terlihat lebih indah atau memiliki nilai estetika.

Selanjutnya Soepratno juga menegaskan tentang bentuk-bentuk ornamen, bahwa ragam hias bermula dari bentuk-bentuk garis lalu berkembang menjadi 9 bermacam-macam bentuk dan beranekaragam coraknya. Adapun yang berupa bentuk-bentuk garis seperti yang disebut di atas dimaksudkan seperti bentuk garis lurus, garis zigzag, garis patah-patah, garis lengkung, garis sejajar dan garis miring. Sedangkan yang dimaksud dengan beraneka ragam bentuk dan coraknya yaitu ornamen tersebut sudah berbentuk dan bercorak seperti bentuk dan corak tumbuhan, hewan, benda-benda alam, dan bisa juga manusia. Ornamen pada suatu bidang atau benda memiliki berbagai variasi motif, karena pada suatu bidang atau benda bisa terdapat satu, dua, tiga atau lebih motifnya, bisa berupa pengulangan motif kombinasi dan ada juga yang digayakan tergantung sama pembuat ornamen atau seperti apa benda atau seluas apa bidang yang menjadi tempat penampungan motif-motif ornamen itu.

\section{SIMPULAN}

Dari paparan di atas mengenai perancangan alternatif signagel sign system sebagai informasi lokasi penjualan di pasar legi Kotagede, peneliti menyimpulkan antara lain:

1. Pasar tradisional adalah tempat bertemu dan interaksi antara penjual dan pembeli. Tempat terjadinya transaksi tawar menawar harga secara langsung. Pasar tradisional tidak sekadar sebagai tempat transaksi jual beli, tetapi juga dapat berkembang 
menjadi lokasi yang multifungsi dan memiliki fungsi sosial dan budaya.

2. Kebutuhan akan suatu signage/ sistem informasi di pasar Legi Kotagede berupa tanda sebagai petunjuk arah yang baik semakin berkembang, khususnya pada kerumunan massa (masyarakat) yang membutuhkan informasi petunjuk arah. Pengunjung merasa akan lebih mudah untuk beraktivitas di dalam suatu bangunan, terutama untuk menemukan alur jalan (wayfinding) atau menemukan lokasi yang dituju. Sign system adalah sebuah sistem penandaan yang sesuai dengan kebudayaan warga masyarakatnya, selain sebagai petunjuk, penamaan, penyampaian informasi singkat, dapat juga berupa aturan-aturan atau normanorma yang dipakai dan diakui pada tempat tertentu dan dapat dimengerti oleh warga masyarakatnya.

3. Peletakan dan konstruksi signage/sign system yang tepat akan mempermudah akses informasi bagi masyarakat dalam berbelanja di daerah Pasar Legi Kotagede Yogyakarta sehingga berbelanja menjadi terarah dan teratur.

4. Signage/ sign system yang efektif akan mengurangi penumpukan keramaian pada titik tertentu dan memudahkan pengunjung untuk menemukan lokasi pedagang yang dituju dan keluar dari pasar Legi Kotagede.

\section{DAFTAR PUSTAKA}

Ensiklopedia Kota Gede. (2009). Dinas Kebudayaan Provinsi Daerah Istimewa Yogyakarta

Gustami, Sp. (2004). Proses Penciptaan Seni Kriya: Untaian Metodologis.
Yogyakarta:

Program

Pascasarjana S2 Penciptaan dan Pengkajian Seni ISI Yogyakarta

Kartika, Rina. (2010). Konsep Visual Sistem Sarana Isyarat Petunjuk (Sign System) Di Kampus Syahdan Binus University. Jurnal Humaniora Vol. 1. No. 2.

Oktavia, G. (2007). Redesain Pasar Jongke Surakarta. Skripsi S1.Fak. Teknik .Jurusan Arsitektur, Universitas Atma Jaya.

Ratna, N.K., (2010). Metodologi Penelitian: Kajian Budaya dan Ilmu-ilmu Sosial Humaniora Pada Umumnya. Yogyakarta: Pustaka Pelajar.

Retnowati. (2011). Bentuk Interaksi antar Pedagang Aksesori Di Emperan Toko(Perko) MALIOBORO Yogyakarta. Yogyakarta: Universitas Negeri Yogyakarta

Rukiah, Y. dan Andrijanto, MS. (2017). Pasar Legi Kotagede Yogyakarta Perancangan Alternatif Perangkat Jualan Di Pasar Legi Kotagede. Jurnal Dimensi Seni Rupa dan Desain Universitas Trisakti Vol 14 - No. 1 - September 2017. Jakarta.

Sadillah, Emiliana dkk. (2011). Eksistensi Pasar Tradisional. Yogyakarta: Balai Pelestarian Sejarahdan Nilai Tradisional.

Setianto, (2008). Masa Depan Pasar Tradisional, Bahan Presentasi CPMU-USDRP Ditjen Cipta Karya.

Soepratno. (1997). Ornamen Ukir Tradisional Jawa II. Semarang: IKIP Semarang Press. 
Tanuwidjaja, G. (2012). Kualitas Elemen Arsitektur sebagai Penunjang Kemudahan Wayfinding dan Orientasi di Gedung Universitas Kristen Petra. Surabaya

Tinarbuko, Sumbo. (2008). Semiotika Komunikasi Visual. Yogyakarta: Jalasutra.

\section{Internet :}

http://www.yogyes.com/id/yogyakartatourism-object/historic-andheritage-sight/kotagede/ http://www.kotagedeheritage.org/index.p $\mathrm{hp} /$ profil-kotagede/situssejarah.html

www.kompasiana.com

http://mesjidgedhe.or.id/filosofi-ukirandan-ornamen/

http://eprints.uny.ac.id/17241/1/Jeksi\%2 0Dorno\%2010207244022.pdf 